present more than 4 infections. The significance of heterozygous HYLX promoter was observed only for the presence of infection. Table 1.

Table 1. Association between MEX-SLEDAI and Infections with MBL structural and promoter genotypes in SLE patients

\begin{tabular}{|c|c|c|c|c|c|c|}
\hline & $\begin{array}{l}\text { MEX-SLEDAI } \\
\text { median (IQR) }\end{array}$ & $p^{*}$ & $\begin{array}{c}\text { Patients with } \\
\text { infections events } \geq 4 \text {, } \\
\mathrm{n}(\%)\end{array}$ & $\begin{array}{c}\text { Total patients with } \\
\text { infections events } \geq 4 \text {, } \\
n(\%)\end{array}$ & $\mathrm{p}^{\star \star}$ & OR \\
\hline Codon $52, n=7$ & & 0.68 & & $12(16.9)$ & 0.44 & \\
\hline $\mathrm{A} / \mathrm{A}$ & $3(6)$ & & $10(17.5)$ & & & \\
\hline$A / D$ & $3(8)$ & & $0(0)$ & & & \\
\hline $\mathrm{D} / \mathrm{D}$ & $1(7)$ & & $2(25)$ & & & \\
\hline Codon $57, n=7$ & & 0.02 & & $13(17.8)$ & 0.03 & $38.7(1.2-58)$ \\
\hline $\mathrm{A} / \mathrm{A}$ & $2(6)$ & & $10(14.7)$ & & & \\
\hline $\mathrm{A} / \mathrm{C}$ & $0(0)$ & & $0(0)$ & & & \\
\hline $\mathrm{C} / \mathrm{C}$ & $9(0)$ & & $3(60)$ & & & \\
\hline Promoter, $\mathrm{n}=74$ & & 0.35 & & $13(17.6)$ & 0.01 & \\
\hline HYHY & $3(7)$ & & $2(18.2)$ & & & \\
\hline LYLY & $2(8)$ & & $5(21.7)$ & & & \\
\hline LXLX & $1.5(6)$ & & $1(4.8)$ & & & \\
\hline LXLY & $2.5(5)$ & & 2 (13.3) & & & \\
\hline HYLY & $5(0)$ & & $1(50)$ & & & \\
\hline HYLX & $0(0)$ & & $2(100)$ & & & \\
\hline
\end{tabular}

MEX-SLEDAI: Mexican Systemic Lupus Erythematosus Disease Activity Index, IQR: interquartile range, OR: Odds ratio. ${ }^{\star}$ Kruskal-Wallis $\mathrm{H}$ test, ${ }^{* \star}$ Chi-square test.

Conclusions: MBL2 gene polymorphisms of the homozygous $\mathrm{C} / \mathrm{C}$ in codon 57 of the structural region and heterozygous HYLX of the promoter region are associated with increased risk of a higher number of infections. Also, we observed that homozygous $\mathrm{C} / \mathrm{C}$ in codon 57 was asociated to a higher MEX-SLEDAI.

Disclosure of Interest: None declared

DOI: 10.1136/annrheumdis-2017-eular.3304

\section{AB0024 A NOVEL REAL-TIME IMAGING TECHNIQUE TO CHARACTERIZE MECHANISMS OF CELL DEATH IN NEUTROPHILS}

S. Gupta ${ }^{1}$, D.W. Chan ${ }^{1}$, K.J. Zaal ${ }^{2}$, E. Ralston ${ }^{2}$, M.J. Kaplan ${ }^{1} .{ }^{1}$ Systemic Autoimmunity Branch; ${ }^{2}$ Light Imaging Section, NIAMS/NIH, Bethesda, United States

Background: Neutrophils play a key role in the pathogenesis of autoimmune diseases through various mechanisms including the formation of neutrophil extracellular traps (NETs). NETosis, a recently described distinct form of program neutrophil cell death, is characterized by reactive oxygen species generation, chromatin and nuclear decondensation, membrane rupture and extrusion of a meshwork of chromatin bound to granule peptides.

Objectives: Techniques to assess and quantitate NETosis in an unbiased, reproducible and efficient way are lacking. We developed a new method to automatically quantify the percentage of neutrophils undergoing NETosis using real-time quantitative live-cell analysis with IncuCyte ZOOM ${ }^{\mathrm{TM}}$ (Essen BioScience, Inc.) platform and a dual-dye system dependent on membrane integrity to stain DNA, to image neutrophils and characterize their mechanisms of cell death.

Methods: Neutrophils were isolated from healthy controls using density gradient methods and their DNA was stained with a membrane permeable NUCLEAR-ID Red DNA dye. Neutrophils were plated and incubated with various stimuli to induce NETosis (PMA, ionomycin and/or SLE sera), apoptosis (Staurosporin) or necroptosis (TNF with a pan-caspase inhibitor, Z-VAD) and with Sytox, a membrane-impermeable DNA dye. Three 20x magnification images from different areas per well were captured at 10-minute intervals. A processing definition was PMA O hour
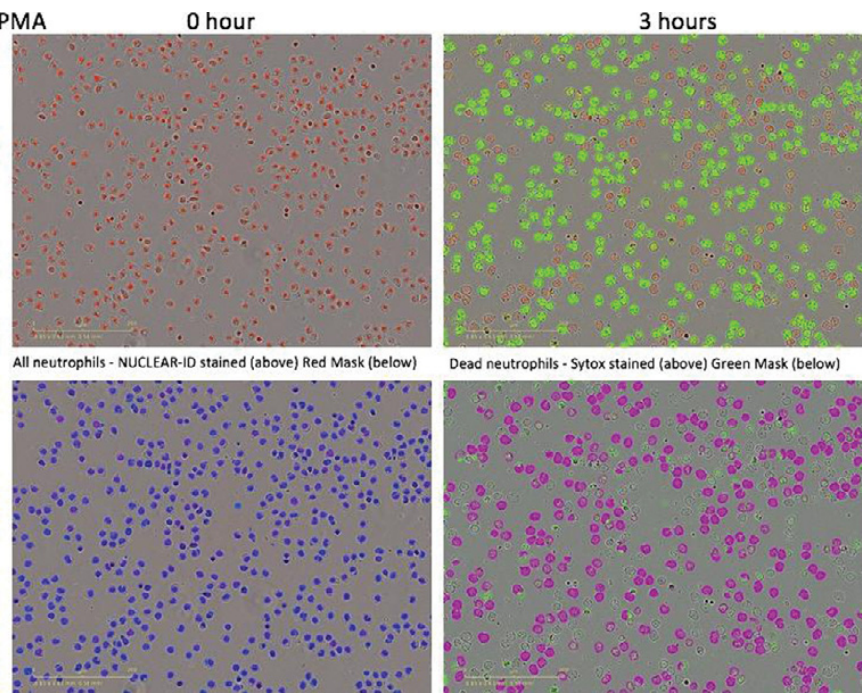

Dead neutrophils - Sytox stained (above) Green Mask (below)

Figure 1 set and optimized to count all neutrophils (NUCLEAR-ID stained) at baseline and neutrophils undergoing cell death (Sytox stained) at three hours using fluorescence intensity and stained area size (Figure 1).

Results: Percentage of neutrophils undergoing cell death using various stimuli was highly reproducible. Characterization of changes in nuclear morphology, quantified by the processing definition, distinguished between NETosis, apoptosis and necroptosis. Findings were confirmed and counts correlated with previously established method using immunofluorescence microscopy.

Conclusions: This novel real time assay distinguishes types of neutrophil cell death and quantifies NETosis in a rapid, accurate and reproducible way. This technique may facilitate studies in neutrophil biology.

Disclosure of Interest: None declared

DOI: 10.1136/annrheumdis-2017-eular.3593

\section{AB0025 PREGNANCY RESULTS IN THE SELECTIVE MODULATION OF PLATELET TISSUE FACTOR EXPRESSION INDEPENDENTLY OF THE PRESENCE OF ANTIPHOSPHOLIPID ANTIBODIES OR OF OTHER AUTOIMMUNE FEATURES}

V. Canti ${ }^{1}$, M.T. Castiglioni ${ }^{2}$, M. Angelo A ${ }^{2}$, P. Rovere-Querini ${ }^{2}$, N. Maugeri ${ }^{2}$. ${ }^{1}$ San Raffaele Scientific Institute, Milano, Italy; ${ }^{2}$ via Olgettina 58, San Raffaele Scientific Institute, Milano, Italy

Background: Neutrophils and platelets are key innate immune cells that productively interact upon activation, generating/releasing moieties that can damage the bystander tissue and prompt vasculogenesis. Successful pregnancy critically depends on a tight regulation of the latter events. Conversely pregnancy complications are associated with alteration/damage of the vasculature associated to the placenta. Blood-born tissue factor (TF) due to the expression of the moiety by platelets and leukocytes has been involved in the pro-thrombotic diathesis associated with sustained human autoimmunity, including that associated with anti-phospholipid syndrome (APS).

Objectives: To test the modulation of parameters related to blood-born TF during normal and pathological pregnancy

Methods: The expression of TF by platelets, monocytes and neutrophils has been studied in 40 women at the 12th week of gestation ( $\mathrm{wg}$ ) including twelve healthy women, 14 patients with insulin-dependent diabetes mellitus (IDDM) and 14 patients with a previous history of pregnancy complications, six of them with APS. 30 healthy age-matched non-pregnant women served as controls. When possible, patients were studied again at least one year after the pregnancy completion. Blood samples were collected and processed as described ${ }^{1,2}$. Other features reflecting cell activation were assessed in parallel ${ }^{1,2}$.

Results: The expression of platelet TF was significantly higher in pregnant women compared with age-matched controls. Platelet P-selectin was as well significantly up-regulated. Neutrophils circulating in all pregnant women were mildly degranulated. The content of the neutrophil secondary granules was depleted in particular in subiects with previous pregnancy complications sine causa.

Conclusions: Our data support the contention that the activation of the innate immune system is a key feature of pregnancy, regardless of the presence of features of systemic or organ-specific autoimmunity. This implies an important modulation of the machinery involved in the reciprocal activation of platelets and neutrophils and in the pro-thrombotic phenotype of circulating cells. The analysis of the potential modulation of these parameters by ongoing treatment is currently being carried out.

References:

[1] Manfredi A \& al. Ann Rheum Dis. 2016;75(8):1511-20. doi: 10.1136/ annrheumdis-2015-208442.

[2] Maugeri N et al. Blood. 2011 Sep 22;118(12):3359-66. doi: 10.1182/blood2011-02-337337.

Disclosure of Interest: None declared

DOI: 10.1136/annrheumdis-2017-eular.6429

\section{Cytokines and inflammatory mediators}

\section{AB0026 CHEMOKINE SIGNALS ARE CRITICAL FOR HOMING AND ENHANCED DIFFERENTIATION OF CIRCULATING OSTEOCLAST PROGENITOR CELLS}

A. Sucur ${ }^{1}$, Z. Jajic ${ }^{2}$, M. Artukovic ${ }^{3}$, M. Ikic Matijasevic ${ }^{3}$, F. Grubisic ${ }^{2}$, B. Anic ${ }^{4}$, S. Ivcevic ${ }^{1}$, D. Flegar ${ }^{1}$, D. Grcevic ${ }^{1}{ }^{1}{ }^{1}$ Department of Physiology and Immunology, University of Zagreb School of Medicine; ${ }^{2}$ Department of Rheumatology, Physical Medicine and Rehabilitation, Clinical Hospital Center "Sestre Milosrdnice", University of Zagreb School of Medicine; ${ }^{3}$ Department of Clinical Immunology and Pulmology, Clinical Hospital "Sveti Duh"; ${ }^{4}$ Department of Clinical Immunology and Rheumatology, Clinical Hospital Center "Zagreb", Zagreb, Croatia

Background: Peripheral blood (PB) monocyte pool contains cells capable of differentiating into osteoclasts (OCs). These osteoclast progenitors (OCPs) contribute to osteoresorption in inflammatory arthritides under influence of the cytokine milieu and chemokine mediated trafficking. 